\title{
A review of health economic studies comparing traditional and massively parallel sequencing diagnostic pathways for suspected genetic disorders
}

Patrick Fahr BSc MSc ${ }^{1 *}$, James Buchanan MA DPhil ${ }^{1,2}$, Sarah Wordsworth MSc PhD ${ }^{1,2}$

1. Health Economics Research Centre, Nuffield Department of Population Health, University of Oxford, Oxford, UK

2. National Institute for Health Research Oxford Biomedical Research Centre, University of Oxford, Oxford, UK

*correspondence to Patrick Fahr, Health Economics Research Centre, Nuffield Department of Population Health, University of Oxford, Old Road Campus, Oxford, OX3 7LF, UK. Telephone: +44(0) 1865 289272. Email: patrick.fahr@dph.ox.ac.uk

ORCID PF (https://orcid.org/0000-0003-2190-1513)

ORCID JB (https://orcid.org/0000-0003-2528-0638)

ORCID SW (https://orcid.org/0000-0002-2361-3040)

Keywords: costing, economic evaluation, diagnostics, genomics, next-generation sequencing

Funding acknowledgement

PF is funded by the German Academic Scholarship Foundation. JB and SW are funded by the National Institute for Health Research Oxford Biomedical Research Centre. 


\begin{abstract}
Genetic disorders are clinically diverse and genetically heterogeneous, and are traditionally diagnosed based on an iterative phenotype-guided genetic assessment. However, such diagnostic approaches are long (diagnostic odysseys are common), misdiagnoses occur frequently, and diagnostic rates are low. Massively parallel sequencing (MPS) technologies may improve diagnostic rates and reduce the time-to-diagnosis for patients with suspected genetic disorders. However, MPS technologies are expensive and the health economic evidence base to support their use is limited. Several studies have compared the costs of traditional and MPS diagnostic pathways for patients with suspected genetic disorders, however costing methods and diagnostic scenarios are heterogeneous across studies. We conducted a literature review to identify and summarise information on these costing methods and diagnostic scenarios. Relevant studies were identified in MEDLINE, EMBASE, EconLit, University of York Centre for Reviews and Dissemination and the Cochrane Library from 2010 to 2018. Twenty four articles were included in the review. We observed considerable heterogeneity across studies with respect to the selection of items of resource use used to derive total diagnostic pathway cost estimates. We also observed structural differences in the diagnostic scenarios used to compare the traditional and MPS diagnostic pathways. There is a need for guidelines on the costing of diagnostic pathways to encourage the use of consistent methods. More micro-costing studies that evaluate diagnostic service delivery are also required. Greater homogeneity in costing approaches would facilitate more reliable comparisons between studies and improve the transferability of cost estimates across countries.
\end{abstract}




\section{Key points}

- Studies that evaluate the costs of traditional and massively parallel sequencing diagnostic pathways exhibit considerable heterogeneity in terms of which elements of resource use are included in these estimates.

- The presence of structural differences in the diagnostic scenarios used to compare traditional and massively parallel sequencing diagnostic pathways prevents a straightforward comparison of cost estimates between studies.

- There is a need for guidelines on the costing of diagnostic pathways to facilitate comparisons between studies. 


\section{Introduction}

Genetic disorders are clinically diverse and genetically heterogeneous diseases caused by alterations in the chemical structure of DNA [1]. Between 4,000 to 6,000 genetic disorders have been defined with a birth prevalence of $1 / 25$ [2]. Patients who are diagnosed with genetic disorders or who present with phenotypic characteristics associated with a genetic disorder, such as early-onset epilepsy, require many medical consultations and complex clinical management, especially if the genotype-phenotype relationship is unclear [3, 4].

Traditionally, iterative phenotype-guided clinical and genetic assessment has been used to diagnose genetic disorders. This involves clinicians seeking to establish a genetic diagnosis based on observable physical patient characteristics, assuming a relationship with the patient's underlying genetic characteristics and potential environmental factors [5]. Besides assessing the patient's medical history and those of family members, phenotype-guided approaches commonly include imaging tests, neurophysiological examinations, and pathology tests. These investigations may be followed by genetic tests, such as those which aim to detect chromosomal abnormalities (for example fluorescence in situ hybridization or karyotyping), or more specific DNA tests focussing on candidate gene testing (testing of genes considered responsible for the patients phenotypical characteristics; for example Sanger sequencing).

Clinical investigations are commonly based on a tiered approach in which specific tests are associated with a particular stage (tier) of the investigation. Movement between tiers often relates to an increase in test complexity. This iterative approach is often time consuming, and patients may attend many hospital appointments before a diagnosis is achieved (known as a diagnostic odyssey). This process can also be invasive for patients and expensive for healthcare systems [6]. Furthermore, although a range of tests are available, some of which are expensive and sophisticated, diagnostic rates are low. For example, Palmer et al. (2017) report a diagnostic yield of $6.2 \%$ with a diagnostic pathway cost per patient of AU $\$ 11,827(\$ 8,382)$ and a cost per diagnosis of AU $\$ 189,242(\$ 134,106)$, following the traditional diagnostic pathway for the diagnosis of epileptic encephalopathies in a patient group for whom first-tier diagnostic testing resulted in no diagnosis [7]. The American College of Medical Genetics and Genomics states that achieving a genetic diagnosis has implications for the selection of appropriate treatments (if available) and the psychological wellbeing of patients and family members [8]. With respect to the latter, there is evidence on the psychological benefits to family members from receiving a diagnosis [9].

Massively parallel sequencing (MPS) technologies enable high-throughput sequencing of DNA with an increased potential to interrogate the human genome for novel causes of diseases. MPS technologies vary in format but sequencing commonly focuses on either a panel of selected genes (targeted MPS), the exome (interrogation of the protein-coding region of the genome, which accounts for $1-2 \%$ of the total genome), or the genome (interrogation of the near-complete genome containing all of the genetic material) [5, 10]. Using these technologies in clinical practice improves diagnostic yield, facilitates a reduction in unnecessary and timeconsuming investigations, and may lead to more timely interventions in patients with suspected rare genetic disorders [6, 11-14]. Palmer et al. (2017) found that following an MPS diagnostic pathway in a patient group for which first-tier diagnostic testing for epileptic encephalopathies resulted in no diagnosis increased diagnostic 
yield from $6.2 \%$ (second-tier diagnostic testing) to $50 \%$ and reduced the cost of the diagnostic pathway by AU $\$ 5,236(\$ 3,710)$ per additional diagnosis [7].

MPS technologies are currently considered to be expensive. Demand for health economic evidence on the use of these technologies has therefore grown prior to their translation into routine clinical care [15]. A recent review of economic evaluations of genome sequencing in a paediatric population found that genome sequencing increased diagnostic effectiveness and decreased the cost of the diagnostic pathway, compared to traditional approaches. However, the authors noted that there is a "need for improvement in the rigour of the methodologies used to provide robust evidence" [16]. In addition, a systematic review on the cost-effectiveness of exome and genome sequencing described issues related to data transparency; several studies presented cost estimates without a clear indication of the items of resource use that were costed [17].

Which items of resource use to include in cost estimates for specific diagnostic approaches is an important consideration, because this information will help health care systems to understand where to invest funds. The appropriate costing approach should generally be guided by the objective of the costing study and the specification of a particular healthcare service [18], both of which can vary considerably with diagnostic testing for genetic disorders. Other considerations include data availability, the purpose of the analysis, and the time and resources available to undertake the study. Costing approaches range from detailed bottom-up micro-costing studies, to more simplistic top-down gross-costing studies using market prices, to the analysis of retrospective reimbursement data based on diagnosis-related groups (with an often less-transparent picture of included items of resource use) [18, 19].

Differences in the range of included resource use items and the level of granularity across economic evaluations of MPS technologies can create several problems. First, it is difficult to understand whether one test or diagnostic pathway consumes more resources than another if there is limited information on used resources, making it challenging to determine the true cost-effectiveness of MPS. Second, comparing cost estimates of diagnostic trajectories between studies is problematic if methodological approaches to estimating costs vary considerably. Third, when parameters are sourced for health economic models, it is difficult to judge which published diagnostic pathway cost estimates are closer to the true costs. Fourth, a lack of data transparency on included items of resource use may prevent the transfer of diagnostic pathway cost estimates across jurisdictions to inform implementation decisions [20]. Increased homogeneity of costing methods would therefore enable more reliable comparisons to be made between studies and improved transferability of cost estimates across jurisdictions.

A further point of consideration is the range of different diagnostic scenarios that are evaluated in studies comparing the costs and effects of different diagnostic pathways. Such scenarios range from a complete substitution of the traditional diagnostic pathway by MPS diagnostic approaches, to the gradual integration of MPS. The choice of the comparative diagnostic scenarios will impact on the conclusions of health economic studies and should be understood in the context of each individual study. 
This paper aims to review health economic studies that have compared traditional and MPS diagnostic pathways. The focus of the review is on the selection of: (1) items of resource use used to derive overall cost estimates of the pathways; and (2) comparative diagnostic scenarios used for health economic comparisons. 


\section{Methods}

\subsection{Overview}

Studies comparing traditional and MPS diagnostic pathways for genetic disorders were selected for inclusion in our review if an economic comparison of both diagnostic pathways was performed. We included both full and partial economic evaluations published between 2010 and 2018. Full economic evaluations, including costeffectiveness analysis and cost-consequence analysis, compare two or more alternative health care interventions and analyse the costs and consequences of these interventions incrementally. Partial economic evaluations, for example a cost analysis or a budget impact analysis, compare alternative health care interventions by exclusively examining their costs[21]. Our search was not limited to specific disease areas or patient groups.

\subsection{Information sources and search}

Five databases were searched: Medline, Embase, EconLit, The Cochrane Library, and Centre for Reviews and Disseminations. The search syntax was developed for three distinct concepts: diagnostics, genomics and health economics. Each of these concepts was defined by various index-terms and free-text words, then combined using "AND" and "OR" operators (See Appendix 1). Given the interdisciplinary nature of the topic, the search syntax was designed to minimise false negatives. We therefore anticipated that the final number of included citations would be small relative to the number of initial citations. To supplement the syntax-driven database search we also included citations known to the authors (including grey literature), but which were not identified by the database search, and we conducted snowballing (the recursive process of searching and aggregating citations found in already included studies) [22].

\subsection{Data collection process}

One reviewer (PF) screened the titles and abstracts of all citations identified in the syntax-driven database search, and reviewed the full-text of all citations that met the inclusion criteria following abstract review. PF also extracted data from all citations. Currency values were adjusted for inflation and converted from local currencies to 2018 US Dollars using purchasing power parities [23].

\subsection{Data items and analysis of results}

For citations meeting the inclusion criteria, we extracted data on sample size, disease area, which items of resource use were costed, overall costs, number of tests and patient visits, which type of MPS was evaluated, what type of economic evaluation was conducted, and which diagnostic scenarios were considered. Studies were classified as either taking a comprehensive or a narrow approach to the costing of the diagnostic pathway. Comprehensiveness was defined as the inclusion of a wide range of items of resource use, including traditional non-genetic investigations, single gene testing and/or microarray analysis and/or gene panels, and patient consultations and admissions. Narrow studies were defined as studies that did not follow a comprehensive approach to the costing of the diagnostic pathway, for example studies that only focused on genetic testing costs or excluded the costs of patient consultations and admissions. 


\subsection{Quality assessment}

The quality of included full economic evaluations was assessed using the Consolidated Health Economic Evaluation Reporting Standards (CHEERS) checklist [24] (See Appendix 2 Supplementary Table S1) . As per a recent study [25], we assigned scores to each of the 24 items $(1=$ item fully addressed; $0.5=$ item partially addressed; $0=$ item not addressed; no score = item not applicable). All items were weighted equally. Nonapplicable items were not considered in the total score calculation. Subsequent to deriving a total quality score, each study was classified as either high quality (scoring $>80 \%$ of the maximum score), average quality (scoring between $50-80 \%$ of the maximum score), or low quality (scoring $<50 \%$ of the maximum score). 


\section{Results}

\subsection{Search results}

A total of 1,504 citations were retrieved from the database search. After removing duplicates, 1,255 unique citations underwent title and abstract screening. A total of 42 citations were eligible for full text review, of which 17 were eligible for inclusion. Seven additional citations, that were known to the authors but not identified by the database search, were also added. A review of the references (snowballing) of these 24 citations did not identify additional citations. A total of 24 citations were included in the review. Figure 1 summarises the selection process.

\subsection{Study characteristics}

All studies were conducted in high income countries [26] and published between 2014 and 2018. The number of included studies increased by year with nine studies (37.5\%) published in 2017. More than half of the studies (14 studies, 58\%) were conducted in the United States (7 studies, 29\%) and Australia (7 studies, 29\%), with a further five studies $(21 \%)$ conducted in The Netherlands.

Sample size and clinical conditions varied between studies. Two studies (8\%) used a hypothetical patient population based on an insurance plan of one million members [27], and a pre-specified expected number of cases tested annually as part of an institutional program [28]. Three studies (13\%) had a sample size of less than 20 patients $[3,29,30]$ with Joshi et al. [30] presenting a case study of only four patients. The majority of studies (14 studies, 58\%) had a sample size of between 21 and 99, and Shashi et al. [31] presented the largest sample $(\mathrm{n}=500)$. Most studies (18 studies, 75\%) presented a patient population with suspected neurogenetic disorders.

Most studies (15,63\%) evaluated exome sequencing as part of the MPS diagnostic pathway. Two studies (8\%) $[28,32]$ evaluated genome sequencing and exome sequencing, three studies $(13 \%)[7,33,34]$ evaluated targeted MPS (gene panel) in addition to exome sequencing, three studies (13\%) [35-37] evaluated targeted MPS, and one study (4\%) [31] did not specify the MPS approach. Ten studies (42\%) were full economic evaluations, all of which were cost-effectiveness analyses except for one cost-consequence analysis [28]. All of the full economic evaluations used diagnostic yield as an outcome measure. Of the 14 partial economic evaluations, 13 (54\%) were cost analyses and one (4\%) was a budget impact analysis [27]. Table 1 summarises the study characteristics.

The quality assessment of the 10 economic evaluations (See Appendix 2 Supplementary Table S2) indicated that the majority of included studies were of average quality $(n=7)$. Three studies were of high quality. On average, studies scored lowest on items related to applying discount rates (item 9), measurement of effectiveness (item 11), analytical methods (item 17), and characterising heterogeneity (item 21).

\subsection{Items of resource use that were costed for the traditional diagnostic pathways}

Table 2 summarises the costs of the diagnostic pathways that were compared in each study. Further detail is provided in Supplementary Table S3 (See Appendix 3). Tables 3a and 3b summarise the elements of resource use that were costed in each study. 
All but one [27] of the 24 studies reported a cost estimate for the traditional diagnostic pathway. Eleven studies $[3,4,7,34,35,38-43]$ applied a comprehensive approach to the costing of the traditional diagnostic pathway. For example, Stark et al. [38] estimated the cost of the traditional diagnostic pathway in suspected monogenic disorders by including an extensive list of items of resource use (cost of genetic appointments, subspecialist appointments, pathology, imaging, neurophysiological tests, genetic testing, and other costs including the shipping of DNA samples).

\subsubsection{Costs of patient consultations and admissions}

Fourteen studies [3, 4, 7, 31, 34-36, 38-44] included the costs of patient consultation and admission when estimating traditional diagnostic pathway costs. Differences in the estimation of overall patient consultation and admission costs existed across studies. For example, Tan et al. [39] included all of the consultation and admission costs associated with the assessments necessary for achieving a diagnosis ( $\$ 2,847$ per individual). Similarly, Stark et al. [38] included the costs of consultation and admission (\$583 per individual) that directly related to achieving a diagnosis, but excluded general patient care costs. Van Nimwegen et al. [40] expanded the range of included patient consultation and admission costs by accounting for emergency and inpatient visits related to diagnostic testing. However, the costs of these visits represented only a fraction ( $\$ 177$ per individual) of the overall consultation and admission cost estimates ( $\$ 4,047$ per individual). In contrast, Vrijenhoek et al. [41] accounted for both day care/consultation costs $(\$ 4,086$ per individual) and hospital-related costs $(\$ 10,089$ per individual), independent of whether they were related to the disease and associated diagnostic efforts. Of these four studies, the first two [38, 39] were full economic evaluations, while the other two [40, 41] were partial economic evaluations.

Nine studies [27-30, 32, 33, 37, 45, 46] did not include the costs associated with patient consultations and admissions when estimating the cost of traditional diagnostic pathways. One study [47] did not state whether patient consultations and admissions were included in overall pathway cost estimates. With the exception of one cost-effectiveness analysis [33], all of these studies were partial economic evaluations.

\subsubsection{Costs of genetic testing}

One study [30] defined the cost estimates of the traditional diagnostic pathway as all diagnostic assessment costs that follow after first-tier procedures and investigations.

Three studies [31, 36, 46] based their cost estimates for the traditional diagnostic pathway mainly on the costs of genetic testing and related consultations. For example, Shashi et al. [31] did not consider the cost of non-genetic diagnostic procedures associated with the traditional diagnostic pathway when estimating diagnostic pathway costs. Sagoo et al. [36] considered the traditional diagnostic pathway as a "genetic testing diagnostic pathway".

Furthermore, Tsiplova et al. [28] used a detailed micro-costing approach to cost the use of first-tier chromosomal microarray analysis as a representation of the traditional diagnostic pathway. Finally, Sabatini et al. [27] conducted a budget-impact analysis that considered the costs of various non-genetic and genetic diagnostic procedures and investigations as part of the traditional diagnostic pathway cost estimates. 


\subsubsection{Cost estimates of the traditional diagnostic pathway}

The cost estimates for traditional diagnostic pathways varied considerably between studies. For example, Howell et al. [35] comprehensively captured a vast range of cost components (including traditional non-genetic investigations, patient admissions and genetic tests) to estimate the cost of the traditional diagnostic pathway for epilepsy (see Table 3a and Supplementary Table 3), resulting in mean diagnostic pathway costs of $\$ 7,312$ per individual. In comparison, Sagoo et al. [36] only included cost components related to genetic testing in suspected genetic disorders, resulting in mean diagnostic pathway costs of $\$ 2,725$ per individual. Cordoba et al. [44] comprehensively captured a vast range of cost components and proposed the estimation of the diagnostic pathway cost in neuro-genetic disorders by counting events defined as unnecessary or recurrent, resulting in a mean diagnostic pathway cost of $\$ 2,487$ per individual. In comparison, Vissers et al. [4] followed a comprehensive approach but did not limit estimation to unnecessary or recurrent events, resulting in a mean diagnostic pathway cost of $\$ 13,813$ per individual.

\subsection{Items of resource use that were costed for the MPS diagnostic pathway}

All but one [32] of the 24 studies reported a cost estimate for the MPS diagnostic pathway. Eleven studies [4, 29-32, 40, 41, 43-46] presented costs for MPS diagnostic pathways based on different sequencing formats (targeted panel sequencing, exome sequencing, genome sequencing). However, these studies did not provide information on which items of resource use were included in the cost estimates. For example, Cordoba et al. [44] reported a cost of $\$ 1,512$ per individual for conducting a singleton exome sequence in their medical centre using the Illumina HiSeq 2500 platform, without indicating which items of resource use were included. Shashi et al. [31] presented research-based and commercial costs for trio MPS (platform not defined) of between $\$ 4,561$ and $\$ 11,401$ per individual, but provided no information on the items of resource use that were costed. Three studies $[4,40,41]$ from The Netherlands reported that the cost of trio exome sequencing was approximately $\$ 4,500$ per individual (platform not defined). However, it was not clear whether these estimates included items of resource use such as the cost of geneticist appointments or Sanger confirmation. All eleven studies were cost analyses.

\subsubsection{Comprehensive costing approach to the MPS diagnostic pathway}

Nine studies [3, 27, 33-39] applied a comprehensive approach to the costing of the MPS diagnostic pathway. These studies included items of resource use related to conducting MPS (sequencing, analysis, reporting of results) and to procedures and investigations commonly required as part of the traditional diagnostic pathway and likely still necessary on an MPS pathway (for example, imaging and microarray analysis). The exact range of included procedures and interventions depended on the underlying diagnostic scenarios and at which point of the traditional diagnostic pathway MPS was integrated. For example, Stark et al. [38] developed several MPS diagnostic pathways based on singleton exome sequencing, reflecting different levels of MPS integration. Such integration ranged from the use of MPS as a last resort diagnostic tool on top of the standard diagnostic pathway (MPS pathway costs of \$6,216 per individual), to MPS replacing some investigations (MPS pathway costs of $\$ 4,385$ per individual; costs of all genetics appointments and various pathology and genetic tests were excluded), and to MPS almost completely substituting the traditional diagnostic pathway (MPS pathway costs of $\$ 2,782$ per individual; only remaining included costs represented microarray analysis). With the exception of one study [27], all of these studies were cost-effectiveness analyses. A comparison of the MPS diagnostic 
pathway costs between the comprehensive studies that conducted singleton exome sequencing [34, 38, 39] showed a cost range of between $\$ 2,782$ and $\$ 9,466$ per individual.

\subsubsection{Narrow costing approach to the MPS diagnostic pathway}

Four studies [7, 28, 42, 47] presented detailed costing information on MPS (sequencing, analysis, reporting of results). However, these studies did not consider the inclusion of further items of resource use (for example traditional non-genetic investigations) as part of the MPS diagnostic pathway. For example, Palmer et al. [7] reported MPS diagnostic pathway cost estimates of $\$ 6,758$ per case, including the cost for DNA extraction, sequencing, Sanger confirmation, reporting of results, and staff time. Lazaridis et al. [47] reported a range of MPS diagnostic pathway cost estimates $(\$ 6,458$ - \$10,022 per case) which reflected the market prices of different sequencing providers and included the cost of sequencing, Sanger confirmation and insurance preauthorisation (the cost of administrative time to obtain confirmation of reimbursement by the health insurance provider). Laboratory costs and the costs associated with specialist consultation added a further $\$ 1,114$ to these estimates. Last, van der Wilt et al. [42] reported MPS diagnostic pathway cost estimates of $\$ 4,942$ per case, which included the costs of sequencing and two sequencing-related consultations.

\subsection{Comparative diagnostic scenarios}

Supplementary Table S4 (See Appendix 3) summarises the comparators, applied scenarios and health economic conclusions for each study.

\subsubsection{Full economic evaluations}

Nine studies [3, 7, 33-36, 38, 39, 42] estimated the cost-effectiveness of an MPS diagnostic pathway compared with a traditional diagnostic pathway. Ewans et al. [3] evaluated how the cost-effectiveness of an MPS diagnostic pathway for intellectual disability varied if exome sequencing was undertaken at either the first clinical genetic review or when initial symptoms presented. Conducting exome sequencing when initial symptoms presented was identified as the cost-effective alternative, resulting in cost savings of $\$ 613$ per additional diagnosis.

Palmer et al. [7] evaluated the cost-effectiveness of an MPS diagnostic pathway for epileptic encephalopathy based exclusively on exome sequencing (no traditional non-genetic investigations), in comparison with a traditional diagnostic pathway based on first- and second-tier testing. The MPS diagnostic pathway was the cost-effective alternative (using in-house laboratory pathway cost estimates), saving $\$ 3,710$ per additional diagnosis. The authors also compared six commercial MPS options (four trio exome services and two MPS gene panel services) with the traditional diagnostic pathway. The cost-effective alternative was an MPS gene panel service, leading to cost savings of $\$ 11,613$ per additional diagnosis.

Schofield et al. [33] examined the cost-effectiveness of an MPS diagnostic pathway for paediatric muscle diseases that included various para-clinical tests and either a gene panel or exome sequencing, compared with a traditional diagnostic pathway. The incremental savings per additional diagnosis $(\$ 17,148)$ were highest for the MPS diagnostic pathway using a gene panel. Although the authors did not conduct an incremental comparison of the two MPS diagnostic pathways, the incremental cost-effectiveness ratio for exome sequencing compared to a gene panel is calculated to be $\$ 46,579$ per additional diagnosis. 
Sagoo et al. [36] compared a traditional diagnostic pathway with two MPS diagnostic pathways for rare and common genetic disorders: the use of an exome sequencing gene panel either in addition to genetic testing (scenario one), or as a first line diagnostic test (scenario two) in addition to baseline testing (including array comparative genomic hybridisation). The authors reported an incremental cost-effectiveness ratio of $\$ 4,824$ per additional diagnosis for scenario one and \$3,348 per additional diagnosis for scenario two. Both diagnostic scenarios resulted in the same number of diagnoses, indicating that scenario two was dominant.

Howell et al. [35] evaluated the cost-effectiveness of six potential MPS diagnostic pathways (representing a gradual integration of MPS into the traditional diagnostic pathway) compared to a traditional diagnostic pathway in infants with severe epilepsies. The first five of these pathways all resulted in 48 diagnoses and the cost-effective alternative was the pathway with the lowest cost (pathway five, \$526,422). However, the authors deemed the sixth pathway, providing two diagnoses less (46 diagnoses) and with a total cost of $\$ 433,363$, as the cost-effective alternative compared to the traditional diagnostic pathway. If pathway six had instead been compared to pathway five, the incremental cost-effectiveness ratio would have been $\$ 46,529$ per additional diagnosis.

The remaining four cost-effectiveness studies [34, 38, 39, 42] employed similar comparative scenarios where the most cost-effective integration of MPS along the traditional diagnostic pathway was investigated and different alternative interventions incrementally compared. Walsh et al. evaluated the cost-effectiveness of ES in a cohort of individuals with peripheral neuropathy by placing ES at either the end of the traditional diagnostic pathway, or at an earlier point. The authors concluded that placing ES at an earlier point in the diagnostic pathway would result in an incremental cost-effectiveness ratio of $\$ 1,687$ per additional diagnosis and would be the cost-effective alternative [34]. Stark et al. evaluated the cost-effectiveness of ES in a cohort of infants with suspected monogenic disorders by placing ES at three points of the diagnostic pathway (ES as a last resort test, ES replacing some tests and investigations from the traditional pathway, and ES as a first-line test). The authors concluded that ES as a first-line test would result in cost savings of $\$ 1,618$ per additional diagnosis compared to the traditional diagnostic pathway and would be the cost-effective alternative [38]. Tan et al. evaluated the costeffectiveness of ES in children with suspected monogenic disorders by employing ES either at the end of the traditional diagnostic pathway, at the first genetics appointment, or at the first tertiary presentation. The authors concluded that ES at the first tertiary presentation would result in cost savings of $\$ 6,613$ per additional diagnosis compared to the traditional diagnostic pathway and would be the cost-effective alternative [39]. Van der Wilt et al. evaluated the cost-effectiveness of ES in children with suspected genetic neurological disorders by employing ES either at the end of the traditional diagnostic pathway or as a first-tier test. The authors concluded that the incremental cost per additional diagnosis for exome sequencing as a first-tier test compared to the traditional pathway was $\$ 11,570$ [42].

\subsubsection{Partial economic evaluations}

Not all of the 13 cost analyses applied different comparative diagnostic scenarios. A selection of five cost analyses that applied distinguishable comparative diagnostic scenarios is presented below. A complete overview of diagnostic scenarios for all of the partial economic evaluations is provided in Supplementary Table S4. 
Monroe et al. [43] evaluated two scenarios in which exome sequencing would either replace genetic and metabolic testing in diagnosed patients (scenario one), or replace genetic testing in undiagnosed patients (scenario two). They reported that scenario one lead to cost savings of $\$ 8,862$ per case, while scenario two lead to cost savings of $\$ 6,717$ per case.

Shashi et al. [31] evaluated a scenario in which the application of an MPS diagnostic pathway subsequent to receiving no diagnosis following the first visit with a geneticist would result in a diagnostic yield of $50 \%$ and a cost per diagnosis of $\$ 22,803$ - less than the $\$ 28,597$ per diagnosis using the traditional diagnostic pathway.

Soden et al. [32] aimed to identify the cost at which MPS applied at symptom onset would be cost-effective given traditional diagnostic pathway costs of $\$ 21,268$ per family and an MPS diagnostic yield of $40 \%$. The authors concluded that both genome sequencing and exome sequencing would be cost-effective at a maximum cost of $\$ 3,336$ per individual and $\$ 8,507$ per family (trio). No information was presented to indicate which of the two sequencing options (singleton or trio sequencing) was the cost-effective alternative.

Van Nimwegen [40] evaluated two scenarios in which exome sequencing either replaced all genetic tests used in a traditional diagnostic pathway (scenario one), or replaced all repeated and burdensome tests and decreased hospital visit costs by $50 \%$ (scenario two). Their results showed that scenario one would lead to cost savings of $\$ 2,238$ per case, while scenario two would lead to cost savings of $\$ 4,129$ per case.

Finally, Vissers et al. [4] evaluated two MPS diagnostic scenarios. In scenario one, if exome sequencing as a first-tier diagnostic approach resulted in a diagnosis, all the costs of the diagnostic procedures and tests associated with the traditional diagnostic pathway were excluded (except for some non-specified tests). In scenario two, if exome sequencing as a first-tier diagnostic approach did not result in a diagnosis, the costs of the traditional diagnostic pathway were included, except for the costs associated with genetic testing. Their results indicated that the MPS diagnostic pathway cost $\$ 5,622$ per case in scenario one, and $\$ 12,973$ per case in scenario two. Compared to the cost of the traditional diagnostic pathway ( $\$ 13,813$ per individual), both scenarios would result in cost savings.

In addition, Sabatini et al. [27] presented a budget impact analysis comparing chromosomal microarray analysis in the context of fragile $\mathrm{X}$ testing versus exome sequencing. In scenario one all patients received chromosomal microarray analysis and fragile $\mathrm{X}$ testing as a first-tier test, followed by exome sequencing of undiagnosed patients. In scenario two, all patients received exome sequencing as a first-tier test, followed by chromosomal microarray analysis and fragile $\mathrm{X}$ testing of undiagnosed patients. In the context of an insurance plan of one million individuals, the authors concluded that scenario one would save $\$ 1.44$ million, while scenario two would increase costs by $\$ 0.96$ million. 


\section{Discussion}

This review has summarised 24 studies that compared the costs of traditional and massively parallel sequencing (MPS) diagnostic pathways in genetic disorders. We observed considerable heterogeneity across studies with respect to the selection of items of resource use used to derive cost estimates. While some studies applied a comprehensive approach to the costing of the traditional diagnostic pathway, including a wide range of items of resource use, other studies took a more narrow approach. All of the studies that applied a comprehensive approach incorporated the costs of traditional non-genetic investigations, genetic testing, and patient consultations and admissions. However, different approaches were taken to cost patient consultations and admissions. Studies that applied a narrow approach mainly focused on the diagnostic costs related to genetic testing, or did not include the cost of patient consultations and admissions, and hardly any studies considered post-diagnosis costs.

We also observed differences in the costing approach for MPS diagnostic pathways. While some studies comprehensively costed this pathway, including sequencing costs and the costs of necessary traditional nongenetic investigations and patient consultations and admissions, other studies only accounted for sequencing costs. In addition, costing approaches in studies that presented patient consultation costs, including genetic counselling, ranged from the presentation of standard costs for a specific number of genetic counselling sessions, to more comprehensive approaches that included micro costing estimates of genetic counselling. Given that the costs of genetic counselling for MPS may span a wide range due to secondary findings, for example, a comprehensive costing of MPS is important. This has been shown in a recent benchmarking study of ES in children with suspected genetic disorders [48]. In studies that only accounted for sequencing costs, a further distinction can be made according to the granularity of costs presented (from market prices of sequencing to a more detailed listing of resource use items). However, given the presence of heterogeneous costing methods, the use of different sequencing approaches (singleton versus trio sequencing) and platforms, and differences in study populations, particularly with respect to sample size and disease area, no clear relationship could be identified between diagnostic pathway costs and study characteristics.

While studies applying a comprehensive costing approach were defined by the inclusion of a broad range of items of resource use, it could be argued that such comprehensiveness could be extended even further, especially in the context of genetic disorders. For instance, no studies applied a societal approach to costing; hence indirect costs to parents of children with genetic disorders, such as travel costs or productivity losses, were excluded. Receiving a diagnosis may conclude a long diagnostic odyssey, reducing or eliminating such indirect costs. This is supported by evidence from a recent study that estimated average travel costs and caregiver productivity losses equivalent to CDN\$1,907 per family and year in children with suspected genetic disorders [49]. Additionally, only one study incorporated the costs incurred due to receiving a diagnosis, for example downstream treatment costs [41]. Although there are few treatment options for many genetic disorders, receiving a diagnosis can result in subsequent changes in treatment for some patients, with important consequences for downstream healthcare costs [50]. Early evidence on this has recently been published. For example, a follow-up study on a publication [38] that was sampled in this review analysed the cost-effectiveness of genomic sequencing early in the diagnostic pathway in light of clinical outcomes beyond the diagnostic yield (for example changes in clinical management or reproductive service use) [51]. Another study analysed the 
long-term economic impact (20-year time horizon) of genomic sequencing for individuals with suspected monogenic disorders [52]. Including such information may allow for more accurate cost estimates to be generated.

Moreover, the costs arising from patient consultations and hospital admissions deserve further consideration. The inclusion of diagnostic-related consultation and admission costs is important for the estimation of total diagnostic pathway costs. However, the inclusion of emergency or inpatient admission costs related to the diagnostic trajectory may be more complicated. This is because the link between these costs and patient disease status might be difficult to disentangle. Additionally, if a particular disease has only a few admissions, excluding emergency or inpatient hospital admission costs from the costing may not be a problem. This can be seen in the van Nimwegen et al. [40] study, where diagnostic-related emergency and inpatient admission costs only represented a fraction of overall consultation and admission cost estimates. Additionally, Vrijenhoek et al. [41] did not distinguish between disease-related and disease-unrelated hospital costs, presenting considerably higher total consultation and admission diagnostic pathway costs in their primary analysis. However, the authors later excluded hospitalisation costs to have a more valid comparator to the MPS diagnostic pathway. Future studies should elaborate on why some costs have been included and others not. Furthermore, little information was provided in the included studies on how disease-related consultation and admission costs were ascertained when retrospective clinical records data was used. A more detailed understanding of this issue may prevent the underor overestimation of the actual costs of diagnosing genetic disorders.

We also observed considerable structural differences in the diagnostic scenarios used to compare the traditional and MPS diagnostic pathways. Some studies used simplistic approaches to compare the costs of different pathways, assuming that MPS can simply replace all traditional diagnostic interventions. Other studies conducted detailed analyses, evaluating the gradual integration of MPS into traditional pathways. Given that most health care systems employ a tier-based diagnostic testing algorithm in which different procedures and investigations are used sequentially [7,35], evaluating the gradual integration of MPS technologies may be more realistic. The analytic quality and comprehensiveness of used diagnostic scenarios was generally higher in full economic evaluations.

In studies that conducted cost-effectiveness analyses, the standard analytical approach was to compare one or more MPS diagnostic pathways relative to the traditional diagnostic pathway. No studies directly compared the cost-effectiveness of different MPS diagnostic pathway alternatives. This is because most of these pathways resulted in the same number of diagnoses and dominant pathways could be identified by comparing pathway costs. Only two studies $[33,35]$ presented two MPS diagnostic pathway alternatives that could have been compared with each other; however neither study performed such a comparison. Had such a comparison been performed, the resulting incremental cost-effectiveness ratio would have approached $\$ 50,000$ per additional diagnosis. This may be more than the commonly used cost-effectiveness threshold. In fact, a study evaluating parent's willingness to pay for a timely diagnosis by means of array genomic hybridization in patients with idiopathic developmental disability showed that the valuation of such benefits may be considerably lower. Based on a discrete choice experiment, parents were willing to pay CDN\$1,118 if the diagnostic approach would lead to twice the number of diagnoses plus a one-week reduction in waiting time, compared with standard diagnostic procedures [53]. 
Regarding the quality assessment of included full economic evaluations, two key areas for improvement were identified. First, existing studies generally lacked detailed descriptions of their analytical methods, for example related to the handling of non-normally distributed cost data, missing data, or the differentiation between disease-related and disease-unrelated healthcare resource use. Second, there was little focus on the characterisation of heterogeneity in population sub-groups. Studies that focus on genetic disorders in general should present cost-effectiveness results per disease sub-group as results may differentiate considerably [36]. Furthermore, accounting for sub-group heterogeneity in patient groups that represent a specific clinical area (for example neurology or autism) but which encompasses various syndromic and non-syndromic forms of the disease is important.

Considering the wider literature on costing methods, two points should be noted. First, in order to reduce bias in economic evaluations, specific guidelines on costing methods should be established. Current methodological guidelines across clinical areas are generally not sufficiently specific to allow for the straightforward comparison of study results [54]. In addition, guidelines on the costing of diagnostic pathways for genetic diseases in the context of MPS do not exist. Consistent and transparent costing methods in this field would allow for a clear understanding of the quantity of health resources consumed by specific tests or diagnostic pathways, and would facilitate comparisons of cost estimates between studies. Standardised methods would also ensure that transparently established cost estimates can be sourced for model-based economic evaluations, and that health policy makers can make use of cost estimates across jurisdictions.

Second, more studies are required that apply a micro-costing approach to estimate the costs of diagnostic pathways in genetic diseases. Extensive diagnostic pathways include many medical interventions and patient consultations and admissions. Using a top-down gross-costing approach based on retrospective reimbursement data may result in a lack of understanding the true costs of the diagnostic pathway [55]. Micro-costing studies are particularly required for testing in heterogeneous patient populations where differences in healthcare resource utilisation may only be detectable by micro-costing in population sub-groups, accounting for the costs of specific tests. Also, evidence indicates that the differences between cost estimates from micro-costing and cross-costing approaches can be between 9 and $66 \%$. It is therefore recommended to move towards microcosting in clinical areas where the costs of investigation / diagnosis-related activities are high [56].

In addition, there are two further points that merit discussion. First, in several of the included studies, the initial cohort of patients with a specific suspected genetic disorder was not representative of the overall population of patients that suffer from such disorder. Rather, these patients were difficult-to-diagnose patients and represented only a sub-group of the patient population. Traditional pathway cost estimates based on such cohorts may considerably overestimate health care resource utilisation. This will impact on cost-effectiveness estimates for MPS. Therefore, it is important to ascertain whether the results of the cost-effectiveness analysis are representative for the whole of the patient population, given the available data and study design, or only for a specific sub-group of patients. An example of this is the study design by Ewans et al. which proposed the use of MPS in patients with intellectual disability (ID) at initial presentation of symptoms [3]. The conclusion of the authors that MPS at initial presentation of symptoms "in a cohort of individuals with ID results in incremental cost savings" is difficult to support with the presented data, given that data was not collected for a cohort of individuals with ID. Second, several studies concluded that MPS was cost saving or cost-effective. However, 
results that indicate cost savings per additional diagnosis do not indicate that the health care intervention as a whole will save costs in comparison to the alternative. An intervention can be cost saving per additional diagnosis but overall still more expensive. In addition, conclusions regarding cost-effectiveness were often not accompanied by a clear definition of a cost-effectiveness threshold.

This is the first literature review to specifically focus on the costing of diagnostic pathways in MPS. Whilst other reviews have considered the cost-effectiveness of MPS approaches [16, 17], our review describes the items of resource use to derive cost estimates of distinct diagnostic pathways. The detailed summaries we have provided of the different costing methods and diagnostic scenarios applied in the included studies are a strength of this review. This information will help health economists to understand the full spectrum of diagnosticrelated items of resource use that could be included in costing studies and economic evaluations of MPS diagnostic approaches, and to understand and contextualise the results of individual studies.

The studies that were included in this review have several limitations. First, most of these studies are retrospective. Such analyses are subject to the availability of cost data, and the range of items of resource use that could have been included may have been limited. For example, patients may have received additional testing outside the clinical environment in which the study took place. Depending on the health care system, tracing such tests may be difficult. In cases where large amounts of retrospective data are available, such data may still be inferior compared to pre-specified data collection in prospective studies. This is because large datasets do not necessarily contain useful high quality data. A situation in which health economists can prospectively plan data collection is favourable. Second, the studies that were included in this review represent a broad clinical spectrum of genetic disorders. Different disorders will require distinct diagnostic approaches. The patient populations evaluated in these studies also likely include difficult-to-diagnose cases presenting rare phenotypic and genotypic relationships. Such cases will also require distinct diagnostic approaches. Third, some studies have conflated phenotype and genotype. For example, Ewans et al. referred to sequencing in Mendelian disorders [3]. However, sequencing was in fact conducted in a cohort of individuals with intellectual disability of unknown causation and only some individuals were diagnosed with a Mendelian disorder. Precise and consistent use of relevant terminology will be important going forward to ensure that comparators are carefully specified. Fourth, all of the studies that were included in this review were published between 2014 and 2018. Given rapid developments in the field of genomics, some diagnostic pathways and algorithmic testing approaches may soon be outdated. Fourth, the sample size of included studies varies considerably. Studies with a small sample size that focus on multiple clinical conditions should be considered with caution when assessing their health economic conclusions; disorder-specific healthcare resource use for diagnostic purposes may be inadequately captured by summary statistics.

There are several limitations to our review. First, our syntax-driven database search did not capture all studies included in the review. However, the review of references (snowballing) found in studies included in the primary sample did not identify additional studies. Given that this is a niche research area, we are confident that we have captured all eligible studies. Second, the level of detail and transparency in each study regarding the selection of items of resource use, and the differences in terminology across studies, may have had an effect on the quality and granularity of extracted data. 
The use of genomic diagnostic tools will likely increase given current technological developments in this field, hence the number of health economic studies evaluating the costs and benefits of such tools will grow.

However, an increase in such studies may not necessarily contribute to the development of a strong evidence base on the health economic impact of genomic diagnostic tools, unless future studies apply a transparent and comprehensive methodological approach aligned with standard health economic practices. If such an approach is taken, the likely transformation of clinical practice in the era of genomic medicine will be accompanied by a strong, evidence-based decision-making process. 


\section{Figures and tables}

Figure 1 - Flow diagram study selection

Table 1 - Study characteristics

\begin{tabular}{|c|c|c|}
\hline Category & Sub-category & Number of studies (\%) \\
\hline \multirow[t]{6}{*}{ Study setting } & Argentina & $1(4 \%)$ \\
\hline & Australia & $7(29 \%)$ \\
\hline & Canada & $3(13 \%)$ \\
\hline & England & $1(4 \%)$ \\
\hline & The Netherlands & $5(21 \%)$ \\
\hline & United States & $7(29 \%)$ \\
\hline \multicolumn{3}{|l|}{ Year of publication } \\
\hline & 2014 & $3(13 \%)$ \\
\hline & 2015 & $2(8 \%)$ \\
\hline & 2016 & $5(21 \%)$ \\
\hline & 2017 & $9(37.5 \%)$ \\
\hline & 2018 & $5(21 \%)$ \\
\hline \multicolumn{3}{|l|}{ Study sample size } \\
\hline & Not specified & $2(8 \%)$ \\
\hline & $<20$ & $3(13 \%)$ \\
\hline & $21-99$ & $14(58 \%)$ \\
\hline & $>99$ & $5(21 \%)$ \\
\hline \multicolumn{3}{|l|}{$\begin{array}{l}\text { Massive parallel sequencing } \\
\text { approach }\end{array}$} \\
\hline & Not specified & $1(4 \%)$ \\
\hline & $\begin{array}{l}\text { Massive parallel sequencing panel } \\
\text { (targeted sequencing) }\end{array}$ & $3(13 \%)$ \\
\hline & Exome sequencing & $15(63 \%)$ \\
\hline & $\begin{array}{l}\text { Massively parallel sequencing panel } \\
\text { (targeted sequencing) and exome } \\
\text { sequencing }\end{array}$ & $3(13 \%)$ \\
\hline & $\begin{array}{l}\text { Both exome sequencing and genome } \\
\text { sequencing }\end{array}$ & $2(8 \%)$ \\
\hline \multicolumn{3}{|l|}{ Economic evaluation } \\
\hline & Full economic evaluation & $10(42 \%)$ \\
\hline & Cost-effectiveness analysis & $9(38 \%)$ \\
\hline & Cost-consequence analysis & $1(4 \%)$ \\
\hline & Partial economic evaluation & $14(58 \%)$ \\
\hline & Cost analysis & $13(54 \%)$ \\
\hline & Budget impact analysis & $1(4 \%)$ \\
\hline
\end{tabular}


Table 2 - Costs of diagnostic pathways

\begin{tabular}{|c|c|c|c|c|c|c|c|c|}
\hline Author (year) & Clinical area & $\mathbf{n}$ & Yield TP & $\begin{array}{c}\text { Cost of TP } \\
\text { (per individual \& } \\
\text { per diagnosis) }\end{array}$ & No of tests & $\begin{array}{l}\text { No of patient } \\
\text { visits }\end{array}$ & $\begin{array}{l}\text { MPS type, yield, } \\
\text { platform }\end{array}$ & $\begin{array}{l}\text { Cost MPS pathway } \\
\text { (per individual \& } \\
\text { per diagnosis }\end{array}$ \\
\hline Cordoba (2018) [44] & Neurogenetic disorders & 40 & ns & $\$ 2,487$ & 1.88 & 4.65 & ES(s), $40 \%$ & $\$ 1,512$ \\
\hline & & & & ns & & & Illumina HiSeq 2500 & ns \\
\hline Demos (2017) [37] & $\begin{array}{l}\text { Epilepsy } \\
\end{array}$ & 50 & ns & $\$ 3,929-\$ 7,246$ & $\mathrm{~ns}$ & ns & Panel, 34\%, & $\$ 2,808$ \\
\hline Ewans (2018) [3] & Intellectual disability & 14 & $0 \%$ & $\begin{array}{c}\text { ns } \\
\$ 7,048\end{array}$ & $1-5$ & $\mathrm{~ns}$ & $\begin{array}{c}\text { Ion Proton } \\
\text { ES(s/t), } 29 \%-43 \%,\end{array}$ & $\begin{array}{c}\mathrm{ns} \\
\$ 7,013-\$ 7,373\end{array}$ \\
\hline & & & & $\mathrm{ns}$ & & & $\begin{array}{l}\text { Illumina HiSeq } 2500 \\
\end{array}$ & $\$ 16,363-\$ 25,313$ \\
\hline Howell (2018) [35] & Epilepsy & 86 & $45 \%$ & $\$ 7,312$ & $\mathrm{~ns}$ & ns & Panel, $56 \%$, & $\$ 5,039-\$ 8,164$ \\
\hline Joshi (2016) [30] & Epilensy & & & $\$ 16,124$ & & & Illumina HiSeq 4000 & $\$ 9,421-\$ 14,628$ \\
\hline & & 4 & $15 \%-51 \%$ & $\frac{\$ 22,126}{\text { ns }}$ & 20.25 & ns & $\begin{array}{l}\text { ES(t), } 100 \%, \\
\text { Illumiseq } 2500\end{array}$ & $\$ 6,618$ \\
\hline Lazaridis (2016) [47] & Genetic disease & 51 & $\mathrm{~ns}$ & $\begin{array}{c}\text { ns } \\
228,597\end{array}$ & $\mathrm{~ns}$ & $\mathrm{~ns}$ & $\begin{array}{c}\mathrm{ES}(\mathrm{t}), 29 \% \\
\mathrm{~ns}\end{array}$ & $\$ 6,458-\$ 10,022(+\$ 1,114)$ \\
\hline Monroe (2016) [43] & Intellectual disability & 17 & $\mathrm{~ns}$ & $\$ 19,224$ & 57 & 65 & $\begin{array}{c}\text { ES(t), } 29 \%, \\
\quad 290\end{array}$ & $\$ 4,681$ \\
\hline Nolan \& Carlson (2016) [29] & Paediatric neurology & 53 & $25 \%$ & $\$ 5,265$ & $\mathrm{~ns}$ & $\mathrm{~ns}$ & $\mathrm{ES}, 48 \%$ & $\$ 2,170-\$ 9,765$ \\
\hline & & & & $\mathrm{ns}$ & & & ns & $\mathrm{ns}$ \\
\hline Palmer (2018) [7] & Epilepsy & 32 & $6.2 \%$ & $\begin{array}{l}\$ 8,382 \\
\$ 134,106\end{array}$ & $\mathrm{~ns}$ & $\mathrm{~ns}$ & $\begin{array}{l}\mathrm{ES}(\mathrm{t}), 50 \% ; \text { Panel, } 37.5 \% \\
\text { ns }\end{array}$ & $\begin{array}{l}\text { Panel: \$4,752; ES: \$6,758 } \\
\text { Panel: \$12,673 ES } \$ 13,516\end{array}$ \\
\hline Richards (2015) [45] & Leukodystrophies & 62 & $34 \%$ & $\frac{\$ 9,385}{\mathrm{~ns}}$ & $\mathrm{~ns}$ & $\mathrm{~ns}$ & $\begin{array}{l}\mathrm{ES}, \mathrm{ns}, \\
\mathrm{ns}\end{array}$ & $\frac{\$ 6,613}{\mathrm{~ns}}$ \\
\hline Sabatini (2016) [27] & $\begin{array}{l}\begin{array}{l}\text { Neurodevelopmental } \\
\text { disorders }\end{array} \\
\end{array}$ & - & $30 \%$ & ns & $\mathrm{ns}$ & $\mathrm{ns}$ & $\begin{array}{l}\mathrm{ES}(\mathrm{s}), 40 \%, \\
\text { ns }\end{array}$ & $\$ 2,646$ \\
\hline Sagoo (2017) [36] & Suspected genetic disorder & 96 & $0 \%$ & $\frac{\$ 2,725}{\mathrm{~ns}}$ & 3 & 3 & $\begin{array}{c}\text { Panel, 42.7\%, } \\
\text { Illumina MSeq / NexSeq }\end{array}$ & $\begin{array}{l}\$ 4,153-\$ 4,785 \\
9,726-\$ 11,203\end{array}$ \\
\hline Sawyer (2014) [46] & Ataxia & 42 & $\mathrm{~ns}$ & $\frac{\$ 6,328}{\mathrm{~ns}}$ & $\mathrm{~ns}$ & $\mathrm{~ns}$ & $\begin{array}{l}\text { ES, 39\%, } \\
\text { Illumina HiSeq } 2000\end{array}$ & 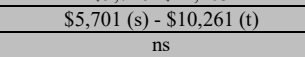 \\
\hline Schofield (2017) [33] & $\begin{array}{l}\text { Paediatric muscle disease } \\
\end{array}$ & 58 & $46 \%$ & $\begin{array}{l}\$ \$ 7,691 \\
\$ 16,566\end{array}$ & $\mathrm{~ns}$ & $\mathrm{~ns}$ & $\begin{array}{l}\text { ES(s/tt), 79\%; Panel, } 75 \% \\
\text { Illumina HiSeq 2000/ 2500s }\end{array}$ & $\begin{array}{l}\text { Panel: \$2,792; ES: \$4,455 } \\
\text { Panel: \$3,722; ES: \$5,670 }\end{array}$ \\
\hline Shashi (2014) [31] & Suspected genetic disease & 500 & $\mathrm{~ns}$ & $\frac{\$ 3,745-\$ 5,383}{\$ 28,597}$ & $\mathrm{~ns}$ & $1.52-1.88$ & $\mathrm{~ns}$ & $\frac{\$ 4,561-\$ 11,401}{\mathrm{~ns}}$ \\
\hline Soden (2014) [32] & $\begin{array}{l}\text { Neurodevelopmental } \\
\text { disorders }\end{array}$ & 119 & $\mathrm{~ns}$ & $\frac{\$ 10,634-\$ 21,268}{\mathrm{~ns}}$ & $7-13.3$ & $\mathrm{~ns}$ & $\begin{array}{c}\text { ES(s/t), } 45 \% ; \text { GS, 73\%, } \\
\text { Illumina HiSeq } 2000 / 2500\end{array}$ & $\begin{array}{l}\mathrm{ns} \\
\mathrm{ns}\end{array}$ \\
\hline Stark (2017) [38] & Monogenic disorders & 40 & $17.5 \%$ & $\begin{array}{l}\$ 3,510 \\
\$ 20,054 \\
\end{array}$ & $\begin{array}{l}42 \% \text { of patients } \\
\text { with } 22 \text { tests }\end{array}$ & $\mathrm{ns}$ & $\begin{array}{l}\mathrm{ES}(\mathrm{s}), 62.5 \%, \\
\text { ns }\end{array}$ & $\frac{\$ 2,782-\$ 6,216}{\$ 4,450-\$ 9,946}$ \\
\hline Tan (2017) [39] & Monogenic disorders & 44 & $0 \%$ & $\$ 7,259$ & 19 & 8 & $\mathrm{ES}(\mathrm{s}), 52 \%$, & $\$ 3,802-\$ 9,466$ \\
\hline & & & & $\mathrm{ns}$ & & & ns & $\$ 7,274-\$ 18,110$ \\
\hline Tsiplova (2017) [28] & Autism disorder & ns & $\mathrm{ns}$ & $\frac{\$ 646}{\mathrm{~ns}}$ & - & - & $\begin{array}{c}\text { ES ; GS, ns } \\
\text { HiSeq } 2500 / \text { HiSeq X }\end{array}$ & $\$ 1,437(\mathrm{ES}) ; \$ 2,476-\$ 4,793(\mathrm{GS})$ \\
\hline Van Nimwegen (2015) [40] & Paediatric neurology & 50 & $6 \%$ & $\$ 16,222$ & 30 & 33 & $\mathrm{ES}(\mathrm{t}), \mathrm{ns}$ & $\$ 4,681$ \\
\hline & & & & ns & & & $n s$ & $\mathrm{~ns}$ \\
\hline $\begin{array}{l}\text { Vissers (2017) }[4] \\
\end{array}$ & Paediatric neurology & 150 & $7.3 \%$ & $\$ 13,813$ & 69 & 23 & $\mathrm{ES}(\mathrm{s} / \mathrm{t}), 29.3 \%$ & $\$ 2,327(\mathrm{~s}) ; \$ 4,523(\mathrm{t})$ \\
\hline $\begin{array}{l}\text { Vrijenhoek (2018) [41] } \\
\end{array}$ & Intellectual disability & 370 & $7 \mathrm{~ns}$ & $\frac{\mathrm{ns}}{\mathrm{Ts}}$ & 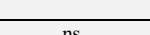 & $3 \mathrm{~s}$ & $\frac{\mathrm{ns}}{\mathrm{FS}(\mathrm{ft}) .350}$ & ns \\
\hline & & & & $\mathrm{ns}$ & & & ns & $\frac{S 4,001}{\mathrm{~ns}}$ \\
\hline van der Wilt (2017) [42] & Paediatric neurology & 100 & $8 \%$ & $\$ 12,091$ & 53 & 20 & $\mathrm{ES}(\mathrm{t}), 30 \%$ & $\$ 4,942$ \\
\hline & & & & $\mathrm{ns}$ & & & ns & ns \\
\hline Walsh (2017) [34] & Peripheral neuropathy & 50 & $0 \%$ & $\$ 2,975$ & 2 & 3.4 & $\begin{array}{l}\text { Panel, } 22 \% \text {; ES(s), } 38 \%, \\
\text { ns }\end{array}$ & $\begin{array}{l}\$ 3,643-\$ 4,703 \\
\$ 9,023-\$ 11,882\end{array}$ \\
\hline
\end{tabular}

(n - sample size; TP - Traditional Pathway; MPS - Massive Parallel Sequencing; ns - not stated; ES - Exome Sequencing; GS - Genome Sequencing; (s) - singleton; (t) - trio) 
Table 3a-Summary of the elements of resource use include for the traditional diagnostic pathway

\begin{tabular}{|c|c|c|c|c|c|}
\hline Author & $\begin{array}{c}\text { Traditional } \\
\text { non-genetic } \\
\text { investigations }\end{array}$ & $\begin{array}{c}\text { Microarray } \\
\text { analysis }\end{array}$ & $\begin{array}{l}\text { Single gene } \\
\text { testing }\end{array}$ & $\begin{array}{l}\text { Panel } \\
\text { testing }\end{array}$ & $\begin{array}{l}\text { Patient consultation / } \\
\text { admission / } \\
\text { counselling }\end{array}$ \\
\hline Cordoba [44] & $\mathrm{X}$ & - & $\mathrm{X}$ & - & $\mathrm{X}$ \\
\hline Demos [37] & $\mathrm{X}$ & $\mathrm{X}$ & $\mathrm{X}$ & - & - \\
\hline Ewans [3] & $\mathrm{X}$ & $\mathrm{X}$ & $\mathrm{X}$ & - & $\mathrm{X}$ \\
\hline Howell [35] & $\mathrm{X}$ & $\mathrm{X}$ & $\mathrm{X}$ & - & $\mathrm{X}$ \\
\hline Joshi [30] & - & - & - & $\mathrm{X}$ & - \\
\hline Lazaridis [47] & \multicolumn{5}{|c|}{ ns } \\
\hline Monroe [43] & $\mathrm{X}$ & - & $\mathrm{X}$ & - & $\mathrm{X}$ \\
\hline Nolan \& Carlson [29] & $\mathrm{X}$ & $\mathrm{X}$ & $\mathrm{X}$ & $\mathrm{X}$ & - \\
\hline Palmer [7] & $\mathrm{X}$ & $\mathrm{X}$ & $\mathrm{X}$ & - & $\mathrm{X}$ \\
\hline Richards [45] & $\mathrm{X}$ & - & $\mathrm{X}$ & - & - \\
\hline Sabatini [27] & $\mathrm{X}$ & $\mathrm{X}$ & $\mathrm{X}$ & $\mathrm{X}$ & - \\
\hline Sagoo [36] & - & - & $\mathrm{X}$ & - & $\mathrm{X}$ \\
\hline Sawyer [46] & - & - & $\mathrm{X}$ & - & - \\
\hline Schofield [33] & $\mathrm{X}$ & $\mathrm{X}$ & $\mathrm{X}$ & - & - \\
\hline Shashi [31] & - & $\mathrm{X}$ & $\mathrm{X}$ & $\mathrm{X}$ & $\mathrm{X}$ \\
\hline Soden [32] & $\mathrm{X}$ & $\mathrm{X}$ & $\mathrm{X}$ & $\mathrm{X}$ & - \\
\hline Stark [38] & $\mathrm{X}$ & $\mathrm{X}$ & $\mathrm{X}$ & $\mathrm{X}$ & $\mathrm{X}$ \\
\hline Tan [39] & $\mathrm{X}$ & $\mathrm{X}$ & - & - & $\mathrm{X}$ \\
\hline Tsiplova [28] & - & $\mathrm{X}$ & - & - & - \\
\hline Van Nimwegen [40] & $\mathrm{X}$ & $\mathrm{X}$ & $\mathrm{X}$ & - & $\mathrm{X}$ \\
\hline Vissers [4] & $\mathrm{X}$ & $\mathrm{X}$ & $\mathrm{X}$ & - & $\mathrm{X}$ \\
\hline Vrijenhoek [41] & $\mathrm{X}$ & $\mathrm{X}$ & $\mathrm{X}$ & - & $\mathrm{X}$ \\
\hline van der Wilt [42] & $\mathrm{X}$ & - & $\mathrm{X}$ & - & $\mathrm{X}$ \\
\hline Walsh [34] & $\mathrm{X}$ & $\mathrm{X}$ & $\mathrm{X}$ & $\mathrm{X}$ & $\mathrm{X}$ \\
\hline
\end{tabular}

(Note: Panel testing is generally defined as MPS. However, some of the included studies considered panel testing as part of the traditional diagnostic pathway. Ns - not stated) 
Table 3b - Summary of the elements of resource use included for the MPS diagnostic pathway

\begin{tabular}{|c|c|c|c|c|c|c|c|}
\hline Author & $\begin{array}{c}\text { Traditional } \\
\text { non-genetic } \\
\text { interventions } \\
\text { from the TP }\end{array}$ & $\begin{array}{l}\text { Single } \\
\text { gene } \\
\text { testing }\end{array}$ & $\begin{array}{l}\text { Micro- } \\
\text { array } \\
\text { analysis }\end{array}$ & $\begin{array}{c}\text { MP } \\
\text { Sequence }\end{array}$ & $\begin{array}{c}\text { MPS } \\
\text { analysis }\end{array}$ & $\begin{array}{c}\text { Sanger } \\
\text { validation }\end{array}$ & $\begin{array}{c}\text { Patient } \\
\text { consultation / } \\
\text { admission / } \\
\text { counselling }\end{array}$ \\
\hline Cordoba [44] & \multicolumn{7}{|c|}{ ns } \\
\hline Demos [37] & $\mathrm{X}$ & - & $\mathrm{X}$ & $\mathrm{X}$ & ns & $\mathrm{X}$ & - \\
\hline Ewans [3] & $\mathrm{X}$ & - & - & $\mathrm{X}$ & $\mathrm{X}$ & $\mathrm{X}$ & $\mathrm{X}$ \\
\hline Howell [35] & $\mathrm{X}$ & $\mathrm{X}$ & $\mathrm{X}$ & $\mathrm{X}$ & $\mathrm{X}$ & $\mathrm{X}$ & $\mathrm{X}$ \\
\hline Joshi [30] & \multicolumn{7}{|c|}{ ns } \\
\hline Lazaridis [47] & - & - & - & $\mathrm{X}$ & $\mathrm{X}$ & $\mathrm{X}$ & $\mathrm{X}$ \\
\hline Monroe [43] & \multicolumn{7}{|c|}{ Based on study by van Nimwegen et al. } \\
\hline Nolan \& Carlson [29] & \multicolumn{7}{|c|}{ ns } \\
\hline Palmer [7] & - & - & - & $\mathrm{X}$ & $\mathrm{X}$ & $\mathrm{X}$ & $\mathrm{X}$ \\
\hline Richards [45] & \multicolumn{7}{|c|}{$\mathrm{ns}$} \\
\hline Sabatini [27] & - & $\mathrm{X}$ & $\mathrm{X}$ & $\mathrm{X}$ & $\mathrm{X}$ & $\mathrm{X}$ & $\mathrm{X}$ \\
\hline Sagoo [36] & $\mathrm{X}$ & - & - & $\mathrm{X}$ & $\mathrm{X}$ & $\mathrm{X}$ & $\mathrm{X}$ \\
\hline Sawyer [46] & \multicolumn{7}{|c|}{$\mathrm{ns}$} \\
\hline Schofield [33] & $\mathrm{X}$ & $\mathrm{X}$ & ns & $\mathrm{X}$ & $\mathrm{X}$ & $\mathrm{X}$ & - \\
\hline Shashi [31] & \multirow{2}{*}{\multicolumn{7}{|c|}{$\begin{array}{l}\mathrm{ns} \\
\mathrm{ns}\end{array}$}} \\
\hline Soden [32] & & & & & & & \\
\hline Stark [38] & $\mathrm{X}$ & $X$ & $\mathrm{X}$ & $\mathrm{X}$ & $\mathrm{X}$ & $\mathrm{X}$ & $\mathrm{X}$ \\
\hline Tan [39] & $\mathrm{X}$ & - & $\mathrm{X}$ & $\mathrm{X}$ & $\mathrm{X}$ & $\mathrm{X}$ & $X$ \\
\hline Tsiplova [28] & - & - & $\mathrm{X}$ & $\mathrm{X}$ & $\mathrm{X}$ & $\mathrm{X}$ & - \\
\hline Van Nimwegen [40] & \multirow{3}{*}{\multicolumn{7}{|c|}{$\begin{array}{l}\mathrm{ns} \\
\mathrm{ns} \\
\mathrm{ns}\end{array}$}} \\
\hline Vissers [4] & & & & & & & \\
\hline Vrijenhoek [41] & & & & & & & \\
\hline van der Wilt [42] & - & - & - & $\mathrm{X}$ & $\mathrm{X}$ & $\mathrm{X}$ & $\mathrm{X}$ \\
\hline Walsh [34] & $\mathrm{X}$ & $\mathrm{X}$ & $\mathrm{X}$ & $\mathrm{X}$ & $\mathrm{X}$ & $X$ & $\mathrm{X}$ \\
\hline
\end{tabular}

(TP - Traditional Pathway; MPS - Massive Parallel Sequencing; ns - not stated) 


\section{References}

1. National Institute of Health. What are genetic disorders? National Human Genome Research Institute. 2015. https://www.genome.gov/19016930/faq-about-genetic-disorders/. Accessed 23 Jan 2019.

2. Genetic Disorders UK. About Genetic Disorders. 2019.

https://www.geneticdisordersuk.org/aboutgeneticdisorders. Accessed 23 Jan 2019.

3. Ewans LJ, Schofield D, Shrestha R, Zhu Y, Gayevskiy V, Ying K et al. Whole-exome sequencing reanalysis at 12 months boosts diagnosis and is cost-effective when applied early in Mendelian disorders. Genetics in Medicine. 2018. doi:https://doi.org/10.1038/gim.2018.39.

4. Vissers L, van Nimwegen KJM, Schieving JH, Kamsteeg EJ, Kleefstra T, Yntema HG et al. A clinical utility study of exome sequencing versus conventional genetic testing in pediatric neurology. Genetics in Medicine.

2017;19(9):1055-63. doi:https://doi.org/10.1038/gim.2017.1.

5. Glossary of Genomics Terms. JAMA. 2013;309(14):1533-5. doi:https://doi.org/10.1001/jama.2013.2950.

6. Iglesias A, Anyane-Yeboa K, Wynn J, Wilson A, Cho MT, Guzman E et al. The usefulness of whole-exome sequencing in routine clinical practice. Genetics in Medicine. 2014;16(12):922.

doi:https://doi.org/10.1038/gim.2014.58.

7. Palmer EE, Schofield D, Shrestha R, Kandula T, Macintosh R, Lawson JA et al. Integrating exome sequencing into a diagnostic pathway for epileptic encephalopathy: Evidence of clinical utility and cost effectiveness. Molecular Genetics \& Genomic Medicine. 2018;6(2):186-99. doi:

https://doi.org/10.1002/mgg3.355.

8. ACMG Board of Directors. Clinical utility of genetic and genomic services: a position statement of the American College of Medical Genetics and Genomics. Genetics in Medicine. 2015;17(6):505.

doi:https://doi.org/10.1038/gim.2015.41.

9. Lenhard W, Breitenbach E, Ebert H, Schindelhauer-Deutscher H-J, Henn W. Psychological benefit of diagnostic certainty for mothers of children with disabilities: lessons from Down syndrome. American Journal of Medical Genetics Part A. 2005;133(2):170-5. doi:https://doi.org/10.1002/ajmg.a.30571.

10. Adams DR, Eng CM. Next-generation sequencing to diagnose suspected genetic disorders. New England Journal of Medicine. 2018;379(14):1353-62. doi:https://doi.org/10.1056/NEJMra1711801.

11. Baynam G, Pachter N, McKenzie F, Townshend S, Slee J, Kiraly-Borri C et al. The rare and undiagnosed diseases diagnostic service - application of massively parallel sequencing in a state-wide clinical service.

Orphanet J Rare Dis. 2016;11(1):77. doi:https://doi.org/10.1186/s13023-016-0462-7.

12. Taylor JC, Martin HC, Lise S, Broxholme J, Cazier J-B, Rimmer A et al. Factors influencing success of clinical genome sequencing across a broad spectrum of disorders. Nature Genetics. 2015;47(7):717.

doi:https://doi.org/10.1038/ng.3304.

13. Wang J, Gotway G, Pascual JM, Park JY. Diagnostic yield of clinical next-generation sequencing panels for epilepsy. JAMA Neurology. 2014;71(5):650-1. doi:https://doi.org/10.1001/jamaneurol.2014.405.

14. Lee H, Deignan JL, Dorrani N, Strom SP, Kantarci S, Quintero-Rivera F et al. Clinical exome sequencing for genetic identification of rare Mendelian disorders. JAMA. 2014;312(18):1880-7.

doi:https://doi.org/10.1001/jama.2014.14604.

15. NHS England. NHS Genomic Medicine Service. 2018. https://www.england.nhs.uk/genomics/nhs-genomicmed-service/. Accessed 24 Jan 2019.

16. Alam K, Schofield D. Economic evaluation of genomic sequencing in the paediatric population: a critical review. European Journal of Human Genetics. 2018:1-7. doi:https://doi.org/10.1038/s41431-018-0175-6. 17. Schwarze K, Buchanan J, Taylor JC, Wordsworth S. Are whole-exome and whole-genome sequencing approaches cost-effective? A systematic review of the literature. Genetics in Medicine. 2018.

doi:https://doi.org/10.1038/gim.2017.247.

18. Mogyorosy Z, Smith P. The main methodological issues in costing health care services: a literature review. York 2005.

19. Raftery J. Costing in economic evaluation. Bmj. 2000;320(7249):1597.

doi:https://doi.org/10.1136/bmj.320.7249.1597.

20. Drummond M, Barbieri M, Cook J, Glick HA, Lis J, Malik F et al. Transferability of economic evaluations across jurisdictions: ISPOR Good Research Practices Task Force report. Value in Health. 2009;12(4):409-18. doi:https://doi.org/10.1111/j.1524-4733.2008.00489.x.

21. Drummond MF, Sculpher MJ, Claxton K, Stoddart GL, Torrance GW. Methods for the economic evaluation of health care programmes. Oxford university press; 2015.

22. Greenhalgh T, Peacock R. Effectiveness and efficiency of search methods in systematic reviews of complex evidence: audit of primary sources. BMJ. 2005;331(7524):1064-5. doi:

https://doi.org/10.1136/bmj.38636.593461.68

23. Shemilt I, Thomas J, Morciano M. A web-based tool for adjusting costs to a specific target currency and price year. Evidence \& Policy: A Journal of Research, Debate and Practice. 2010;6(1):51-9.

doi:https://doi.org/10.1332/174426410X482999. 
24. Husereau D, Drummond M, Petrou S, Carswell C, Moher D, Greenberg D et al. Consolidated health economic evaluation reporting standards (CHEERS) - explanation and elaboration: a report of the ISPOR health economic evaluation publication guidelines good reporting practices task force. Value in Health.

2013;16(2):231-50. doi: https://doi.org/10.1136/bmj.f1049.

25. Buchanan J, Wordsworth S. Welfarism versus extra-welfarism: can the choice of economic evaluation approach impact on the adoption decisions recommended by economic evaluation studies?

PharmacoEconomics. 2015;33(6):571-9. doi:https://doi.org/10.1007/s40273-015-0261-3.

26. The World Bank. World Bank Country and Lending Group. 2019.

https://datahelpdesk.worldbank.org/knowledgebase/articles/906519-world-bank-country-and-lending-groups.

Accessed 29 Jan 2019.

27. Sabatini LM, Mathews C, Ptak D, Doshi S, Tynan K, Hegde MR et al. Genomic Sequencing Procedure Microcosting Analysis and Health Economic Cost-Impact Analysis: A Report of the Association for Molecular Pathology. Journal of Molecular Diagnostics. 2016;18(3):319-28.

doi:https://doi.org/10.1016/j.jmoldx.2015.11.010.

28. Tsiplova K, Zur RM, Marshall CR, Stavropoulos DJ, Pereira SL, Merico D et al. A microcosting and costconsequence analysis of clinical genomic testing strategies in autism spectrum disorder. Genetics in Medicine. 2017;19(11):1268-75. doi:https://doi.org/10.1038/gim.2017.47.

29. Nolan D, Carlson M. Whole Exome Sequencing in Pediatric Neurology Patients: Clinical Implications and Estimated Cost Analysis. Journal of Child Neurology. 2016;31(7):887-94.

doi:https://doi.org/10.1177/0883073815627880.

30. Joshi C, Kolbe DL, Mansilla MA, Mason SO, Smith RJ, Campbell CA. Reducing the Cost of the Diagnostic Odyssey in Early Onset Epileptic Encephalopathies. Biomed Res Int. 2016;2016:6421039.

doi:https://doi.org/10.1155/2016/6421039.

31. Shashi V, McConkie-Rosell A, Rosell B, Schoch K, Vellore K, McDonald M et al. The utility of the traditional medical genetics diagnostic evaluation in the context of next-generation sequencing for undiagnosed genetic disorders. Genetics in Medicine. 2014;16(2):176-82. doi:https://doi.org/10.1038/gim.2013.99. 32. Soden SE, Saunders CJ, Willig LK, Farrow EG, Smith LD, Petrikin JE et al. Effectiveness of exome and genome sequencing guided by acuity of illness for diagnosis of neurodevelopmental disorders. Science Translational Medicine. 2014;6(265):265ra168. doi:https://doi.org/10.1126/scitranslmed.3010076 33. Schofield D, Alam K, Douglas L, Shrestha R, MacArthur DG, Davis M et al. Cost-effectiveness of massively parallel sequencing for diagnosis of paediatric muscle diseases. NPJ Genomic Medicine. 2017;2(1):4. doi:https://doi.org/10.1038/s41525-017-0006-7.

34. Walsh M, Bell KM, Chong B, Creed E, Brett GR, Pope K et al. Diagnostic and cost utility of whole exome sequencing in peripheral neuropathy. Annals of Clinical and Translational Neurology. 2017;4(5):318-25. doi: https://doi.org/10.1002/acn3.409.

35. Howell KB, Eggers S, Dalziel K, Riseley J, Mandelstam S, Myers CT et al. A population-based costeffectiveness study of early genetic testing in severe epilepsies of infancy. Epilepsia. 2018;59(6):1177-87. doi: https://doi.org/10.1111/epi.14087.

36. Sagoo GS, Norbury G, Mohammed S, Kroese M. Whole exome sequencing in clinical genetics - a health economic evaluation.: PHG Foundation 2017.

37. Demos M, Guella I, McKenzie MB, Buerki SE, Evans DM, Toyota EB et al. Diagnostic Yield And Treatment Impact Of Targeted Exome Sequencing In Early-Onset Epilepsy. bioRxiv. 2017:139329.

doi:https://doi.org/10.1101/139329

38. Stark Z, Schofield D, Alam K, Wilson W, Mupfeki N, Macciocca I et al. Prospective comparison of the cost-effectiveness of clinical whole-exome sequencing with that of usual care overwhelmingly supports early use and reimbursement. Genetics in Medicine. 2017;19(8):867-74. doi:https://doi.org/10.1038/gim.2016.221. 39. Tan TY, Dillon OJ, Stark Z, Schofield D, Alam K, Shrestha R et al. Diagnostic impact and costeffectiveness of whole-exome sequencing for ambulant children with suspected monogenic conditions. JAMA Pediatrics. 2017;171(9):855-62. doi:https://doi.org/10.1001/jamapediatrics.2017.1755.

40. van Nimwegen KJ, Schieving JH, Willemsen MA, Veltman JA, van der Burg S, van der Wilt GJ et al. The diagnostic pathway in complex paediatric neurology: a cost analysis. European Journal of Paediatric Neurology. 2015;19(2):233-9. doi:https://doi.org/10.1016/j.ejpn.2014.12.014.

41. Vrijenhoek T, Middelburg EM, Monroe GR, van Gassen KL, Geenen JW, Hövels AM et al. Whole-exome sequencing in intellectual disability; cost before and after a diagnosis. European Journal of Human Genetics. 2018;26(11):1566. doi:https://doi.org/10.1038/s41431-018-0203-6.

42. van der Wilt GJ, van Nimwegen KJM, Vissers LELM, Schieving JH, Willemsen MAAP, Veltman JA et al. Cost-effectiveness of diagnostic whole exome sequencing in complex paediatric neurology.: Radboud University Nijmegen; 2017. 
43. Monroe GR, Frederix GW, Savelberg SM, de Vries TI, Duran KJ, van der Smagt JJ et al. Effectiveness of whole-exome sequencing and costs of the traditional diagnostic trajectory in children with intellectual disability. Genetics in Medicine. 2016;18(9):949-56. doi:https://doi.org/10.1038/gim.2015.200.

44. Cordoba M, Rodriguez-Quiroga SA, Vega PA, Salinas V, Perez-Maturo J, Amartino H et al. Whole exome sequencing in neurogenetic odysseys: An effective, cost- and time-saving diagnostic approach. PLoS ONE.

2018;13(2):e0191228. doi: https://doi.org/10.1371/journal.pone.0191228.

45. Richards J, Korgenski EK, Taft RJ, Vanderver A, Bonkowsky JL. Targeted leukodystrophy diagnosis based on charges and yields for testing. Am J Med Genet A. 2015;167a(11):2541-3. doi:

https://doi.org/10.1002/ajmg.a.37215.

46. Sawyer SL, Schwartzentruber J, Beaulieu CL, Dyment D, Smith A, Chardon JW et al. Exome Sequencing as a Diagnostic Tool for Pediatric-Onset Ataxia. Human Mutation. 2014;35(1):45-9. doi:

https://doi.org/10.1002/humu.22451.

47. Lazaridis KN, Schahl KA, Cousin MA, Babovic-Vuksanovic D, Riegert-Johnson DL, Gavrilova RH et al. Outcome of Whole Exome Sequencing for Diagnostic Odyssey Cases of an Individualized Medicine Clinic: The Mayo Clinic Experience. Mayo Clin Proc. 2016;91(3):297-307.

doi:https://doi.org/10.1016/j.mayocp.2015.12.018.

48. Dragojlovic N, Elliott AM, Adam S, van Karnebeek C, Lehman A, Mwenifumbo JC et al. The cost and diagnostic yield of exome sequencing for children with suspected genetic disorders: a benchmarking study. Genetics in Medicine. 2018;20(9):1013-21. doi:https://doi.org/10.1038/gim.2017.226.

49. Dragojlovic N, van Karnebeek CD, Ghani A, Genereaux D, Kim E, Birch P et al. The cost trajectory of the diagnostic care pathway for children with suspected genetic disorders. Genetics in Medicine. 2019:1-9.

doi:https://doi.org/10.1038/s41436-019-0635-6.

50. Retterer K, Juusola J, Cho MT, Vitazka P, Millan F, Gibellini F et al. Clinical application of whole-exome sequencing across clinical indications. Genetics in Medicine. 2016;18(7):696.

doi:https://doi.org/10.1038/gim.2015.148.

51. Stark Z, Schofield D, Martyn M, Rynehart L, Shrestha R, Alam K et al. Does genomic sequencing early in the diagnostic trajectory make a difference? A follow-up study of clinical outcomes and cost-effectiveness. Genetics in Medicine. 2018:1-8. doi:https://doi.org/10.1038/s41436-018-0006-8.

52. Schofield D, Rynehart L, Shresthra R, White SM, Stark Z. Long-term economic impacts of exome sequencing for suspected monogenic disorders: diagnosis, management, and reproductive outcomes. Genetics in Medicine. 2019:1. doi:https://doi.org/10.1038/s41436-019-0534-x.

53. Regier DA, Friedman JM, Makela N, Ryan M, Marra CA. Valuing the benefit of diagnostic testing for genetic causes of idiopathic developmental disability: Willingness to pay from families of affected children. Clinical Genetics. 2009;75(6):514-21. doi: https://doi.org/10.1111/j.1399-0004.2009.01193.x.

54. Frappier J, Tremblay G, Charny M, Cloutier LM. Costing bias in economic evaluations. 2015. doi:https://doi.org/10.3111/13696998.2015.1033423.

55. Xu X, Nardini HKG, Ruger JP. Micro-costing studies in the health and medical literature: protocol for a systematic review. Systematic reviews. 2014;3(1):47. doi:https://doi.org/10.1186/2046-4053-3-47.

56. Heerey A, McGowan B, Ryan M, Barry M. Microcosting versus DRGs in the provision of cost estimates for use in pharmacoeconomic evaluation. Expert review of pharmacoeconomics \& outcomes research.

2002;2(1):29-33. doi:https://doi.org/10.1586/14737167.2.1.29. 


\section{Conflict of interest}

PF declares no conflict of interest. JB and SW are co-applicants of a project funded through Genome British Columbia's GeneSolve program and Illumina. JB and SW have received travel funding from Illumina to attend conferences.

\section{Acknowledgement}

PF initiated and led the study, designed the literature review, extracted and tabulated data, interpreted the results and drafted the manuscript. JB assisted with the interpretation of the results, and reviewed and modified the manuscript for important intellectual content. SW assisted with the interpretation of the results, and reviewed and modified the manuscript for important intellectual content. All authors approved the final manuscript. PF acts as the overall guarantor for this work. 